Piotr Korczyński', Katarzyna Górska', Piotr Jankowski , Jakub Kosiński², Agata Kudas², Katarzyna Sułek², Maria Jankowska², Kaja Jaśkiewicz' ${ }^{2}$, Rafał Krenke ${ }^{1}$

'Department of Internal Medicine, Pulmonary Diseases and Allergy, Medical University of Warsaw, Poland

${ }^{2}$ Students Scientific Group „Alveolus”, Department of Internal Medicine, Pulmonary Diseases and Allergy, Medical University of Warsaw, Poland

\title{
Public spirometry campaign in chronic obstructive pulmonary disease screening — hope or hype?
}

The authors declare no financial disclosure

\begin{abstract}
Introduction: Underdiagnosis of COPD seems to be a relevant clinical and social problem. We hypothesized that active public spirometry campaign may help identify subjects with airflow limitation consistent with COPD.

The aim of the study was (1) to evaluate the willingness of random smokers to undergo public spirometry, (2) to assess the ability to obtain an acceptable quality spirometry during a public campaign, and (3) to assess the relationships between the presence and severity of respiratory symptoms and readiness to undergo spirometry.

Material and methods: Pedestrians aged $>40$ years and a smoking history $>10$ pack-years were recruited by medical students to fill a questionnaire and perform spirometry. Those with obstructive or borderline ventilatory insuffciency were invited and encouraged to undergo stationary spirometry in a pulmonary outpatient department.

Results: Nine hundred and five subjects meeting the inclusion criteria were invited to the study. Only 178 subjects agreed to complete the questionnaire and undergo spirometry. Airway obstruction and borderline spirometry result (classified as possible airway obstruction) were found in 22 and 37 subjects, respectively. Of these, only 15 patients attended follow-up visit to verify public spirometry results. Extrapolation of the limited data showed the incidence of newly diagnosed airway obstruction as $10.7 \%$. Conclusions: Public spirometry campaign does not seem to be an effective way of COPD screening. Smokers are reluctant to undergo complimentary spirometry even in the presence of pronounced respiratory symptoms. Our observations may be helpful in elaborating future screening programs for COPD.
\end{abstract}

Key words: airway obstruction, chronic obstructive pulmonary disease, public spirometry

Adv. Respir. Med. 2017; 85: 143-150

\section{Introduction}

Chronic obstructive pulmonary disease (COPD) is a common entity characterized by persistent airflow limitation and respiratory symptoms [1]. According to one recent meta-analysis of 123 studies, the prevalence of COPD in people aged 30 years or older was approximately $11.7 \%$ (95\% confidence interval [CI] 8.4-15.0\%) [2]. With more than 3 million people dying of COPD every year [3] the disease is currently the fourth world leading cause of death and is estimated to become the third in the next several years [1].
Polish epidemiological data on COPD are consistent with those reported from other countries. Three studies showed the prevalence of COPD in Polish population aged $>40$ years ranging between 10.7 and $22.1 \%$ [4-6]. As in other countries, an early diagnosis seems to be one of the major issue in management of COPD. Bednarek et al. [5] showed that in primary care setting only less than $20 \%$ of patients with COPD had been diagnosed. Most of these patients had severe and very severe airflow limitation. Thus, it might be estimated that about $80 \%$ of COPD patients in Poland suffered

Address for correspondence: Katarzyna Górska, Department of Internal Medicine, Pulmonary Diseases and Allergy, Medical University of Warsaw, Poland,

e-mail:drkpgorska@gmail.com

DOI: 10.5603/ARM.2017.0024

Received: 11.04 .2017

Copyright (C) 2017 PTChP

ISSN 2451-4934 
from mild or moderate disease and had been underdiagnosed [7].

As smoking is a major risk factor for COPD, it may seem that the identification of the population at particular risk of COPD development should be relatively simple. One recent Polish study showed that approximately $30 \%$ of men and $21 \%$ surveyed in 2014 were current smokers [8]. These patients should probably be a target for screening campaigns aimed at an early diagnosis of airway obstruction and COPD. However, it has been well documented that asymptomatic smokers or smokers with mild symptoms only rarely seek medical attention. Moreover, primary care providers do not always have access, enough time or adequate training to use spirometry, which is crucial for diagnosis of persistent airflow limitation. Thus, albeit early detection and proper intervention for COPD could potentially slow the progression of the disease and minimize its negative consequences [9], spirometry is probably still performed too rarely to significantly increase the proportion of patients diagnosed with early COPD stages. We believe that social campaigns, including those carried out by medical students, may increase public awareness of COPD, contribute to more effective smoking cessation and more effective COPD diagnosis in patients with mild symptoms.

Therefore, we undertook a study aimed at:

1. The evaluation of willingness of random smokers to undergo public spirometry.

2. The assessment of ability to obtain an acceptable quality spirometry during a public campaign, which could be a prerequisite for the diagnosis of airway obstruction and COPD.

3. The assessment of the relationships between readiness to undergo free of charge spirometry and the presence and severity of respiratory symptoms.

\section{Material and methods}

\section{Study design and patient characteristics}

This prospective, cross-sectional study was conducted between January and May 2016. The recruitment to the study was performed at the Warsaw East Railway Station and included pedestrians who were asked and encouraged to participate in the study. The specific inclusion criteria were as follows: 1) age $>40$ years; 2) a smoking history $>10$ pack-years; 3 ) consent to take part in the study. Subjects with symptoms of acute respiratory tract infection in the previous 6 weeks and those who did not give their consent to participate in the study were excluded. The participants who were active smokers or who had quitted smoking in the last 12 months were classified as current smokers. Subjects who had a smoking history $>10$ pack-years but who had not smoked for more than 12 months were classified as ex-smokers.

A stand was prepared and driven by the medical students. The students actively searched and recruited the study participants. All subjects who met the inclusion criteria and signed the informed consent to participate in the study were asked to fill a questionnaire that contained questions on demographic data, exposure to active and passive smoking, comorbidities and respiratory symptoms. Participants who agreed to perform spirometry, but were non-smokers or $<40$ years of age were excluded from study. Quantitative assessment of symptoms included the COPD Assessment Test (CAT) and the modified Medical Research Council (mMRC) dyspnea scale. Based on the results of the above tests, the patients were classified as having low (mMRC score $0-1$ and CAT score $<10$ ) or high level of symptoms (mMRC $\geq 2$ or CAT score $\geq 10$, respectively) [1]. A portable spirometer (MicroLab 3500, CareFusion, San Diego, California) was used to perform a public spirometry. The measurements were performed by properly trained medical students in accordance with the recommendations of the European Respiratory Society (ERS) and American Thoracic Society (ATS) [10, 11]. Reference values published by the European Coal and Steel Community (ECCS) were applied [12].

To simplify the assessment of public spirometry fixed $\mathrm{FEV}_{1} / \mathrm{FVC}$ ratio below 0.7 was used to diagnose airway obstruction. This approach was concordant with GOLD recommendations [1]. However, to minimize the risk of false negative diagnosis of airway obstruction, the spirometry results with $\mathrm{FEV}_{1} / \mathrm{FVC}$ ratio $\geq 0.7$ but only in subjects with symptoms suggestive for COPD and at the same time unable to perform good quality spirometry were also considered as probable airway obstruction. Thus, based on public spirometry the patients were classified as follows: no airflow limitation group $(\mathrm{N})$ characterized by $\mathrm{FEV}_{1} / \mathrm{FVC}$ ratio $\geq 0.7$ and no respiratory symptoms, airway obstruction group (AO) defined as $\mathrm{FEV}_{1} / \mathrm{FVC}$ ratio $<0.7$ and possible airway obstruction group (PAO) defined as $\mathrm{FEV}_{1} / \mathrm{FVC}$ ratio $<0.7$ and $\mathrm{FEV}_{1} / \mathrm{FVC}$ ratio $\geq 0.7$ and below LLN in symptomatic patients unable to perform spirometry of good quality.

In order to verify the results of public spirometry all participants from $\mathrm{AO}$ and $\mathrm{PAO}$ groups were strongly encouraged to visit a Pulmonary Function Test (PFT) Unit of the Medical Universi- 
ty of Warsaw in order to undergo a free of charge spirometry carried out by qualified medical staff and to be seen by pulmonary specialist. The subjects asked to consult the doctor at the medical centre were inhabitants of the city, where the test was performed. They initially declared the responsible will to come for the check-up and they could select the appointment date. The authors made every effort to motivate the planned group to come for a control spirometry tests. In patients who accepted the invitation, spirometry with flow-volume curve was performed (Lungtest 1000, MES, Cracow, Poland) in accordance with the recommendations of the ERS/ATS [10, 11]. In case of airflow limitation (defined as $\mathrm{FEV}_{1} / \mathrm{FVC}$ $<$ LLN), the bronchial obstruction reversibility test was performed according to the respective guidelines [11].

The study was approved by the institutional review board of the Medical University of Warsaw.

\section{Data presentation and statistical analyses}

Statistical analysis was performed using Statistica 12.5 (StatSoft Inc., Tulsa, OK, USA) and MedCalc 13.2.2 (MedCalc Software bvba, Ostend, Belgium) statistical software packages. Data are expressed as medians and interquartile ranges (IQRs, $25^{\text {th }}$ to $75^{\text {th }}$ percentiles) or numbers and percentages. The distribution of categorical variables in the independent groups was compared using Fisher's exact or Chi square tests. The differences between continuous variables in two or more groups were tested with the use of nonparametric Mann-Whitney U-test or Kruskal-Wallis test with the subsequent use of the post-hoc Dunn test (for multiple comparisons), respectively. Statistical significance was accepted at $\mathrm{p}$-value less than 0.05 .

\section{Results}

One thousand fifty five passers-by were asked to participate in the study, 150 of them were unsuitable (age under 40 years, non-smokers, no answer). Finally, nine hundred five persons who were smokers and aged above 40 years were invited to the study. One hundred seventy eight subjects agreed to stop for a while to complete the questionnaire and undergo spirometry. These patients formed a baseline study group. The remaining 727 subjects $(80 \%)$ refused to collaborate. A detailed characteristic of the study group is presented in Table 1. Based on the results of public spirometry $\mathrm{AO}$ and PAO was diagnosed in $22(12 \%)$ and 37 (21\%) patients, respectively. In the remaining 119 cases (67\%), spirometry showed normal results. Comparative data of patients with normal spirometry, AO and PAO are shown in Table 1.

Only 15 (25\%) of 59 patients with AO and PAO attended the visit in the PFT Unit: 6 participants from the AO group (27\%) and 9 from the PAO group (24\%) (Fig. 1). In 5 patients from the AO group (83\%) and 2 patients from PAO group (22\%) the airway obstruction was confirmed by second spirometry. Thus, airway obstruction was confirmed in $7 / 15$ patients with positive screening by public spirometry. All patients with confirmed airflow limitation had persistent ("fixed") airway obstruction.

The participants who came for a check-up visit were significantly older than subjects who did not seek further medical attention. Also, the percentage of ex-smokers was significantly higher among patients attended follow up visit (Table 2).

In all 5 patients with known COPD, airway obstruction was demonstrated in public spirometry. Two of these patients came for a second assessment and persistent airflow limitation was confirmed in a repeated spirometry. In 2 of 5 patients with known asthma, airway obstruction was found in public spirometry, while 3 asthmatics had normal spirometry. One of them attended the check-up visit and had normal second spirometry. Thus, 5 of 7 (71\%) patients with confirmed airflow limitation had newly diagnosed airway obstruction consistent with diagnosis of COPD.

The similar severity of bronchial obstruction in the public spirometry and stationary spirometry was observed. FEV ${ }_{1}$ and FVC were not significantly different during the test performed on the railway station and in the PFT Unit $(\mathrm{n}=15 ; \mathrm{p}=$ 0.16 and 0.64 , respectively).

\section{Analysis of symptoms in the study group}

Seventy one $(40 \%)$ and $107(60 \%)$ patients who underwent public spirometry had CAT score $\geq 10$ and $<10$ points, respectively. The proportion of patients with CAT score $\geq 10$ points in AO and PAO groups was significantly higher than in $\mathrm{N}$ group (56\% vs. $32 \%$, respectively, $\mathrm{p}=0.003$ ) (Fig. 2). Ten of 15 patients who attended follow up visit and underwent second spirometry reported CAT score $\geq 10$ points, while the remaining 5 patients $<10$ points $(\mathrm{p}=0.381)$. Only 2 of these 15 patients had severe dyspnea according to mMRC scale. The differences between the results of scoring patients with mMRC and CAT are presented in Figure 3. Among AO and PAO patients, the proportion of symptomatic patients evaluated in CAT was significantly higher than 
Table 1. Comparison of study groups classified according to the results of public spirometry

\begin{tabular}{|c|c|c|c|c|c|c|}
\hline & $\begin{array}{c}\text { All subjects } \\
n=178\end{array}$ & $\begin{array}{l}N \text { group } \\
n=119\end{array}$ & $\begin{array}{c}A 0 \text { group } \\
n=22\end{array}$ & $\begin{array}{c}\text { PAO group } \\
n=37\end{array}$ & $\begin{array}{c}p \\
\text { (Kruskal-Wallis } \\
\text { or Chi square } \\
\text { test) }\end{array}$ & $\begin{array}{c}\text { p for multiple } \\
\text { comparisons: } \\
\text { N-AO (a), } \\
\text { N-PAO (b), } \\
\text { AO-PAO (c) }\end{array}$ \\
\hline Age (years) & $56(48-61)$ & $55(47-60)$ & $60.5(51-64)$ & $59(52-63)$ & 0.022 & $\begin{array}{c}0.08^{\mathrm{a}}, 1.0^{\mathrm{b}} \\
0.13^{\mathrm{c}}\end{array}$ \\
\hline $\operatorname{Sex}(F / M)$ & $65 / 113$ & $49 / 70$ & $7 / 15$ & $9 / 28$ & 0.157 & \\
\hline $\mathrm{BMI}\left(\mathrm{kg} / \mathrm{m}^{2}\right)$ & $\begin{array}{c}27.7 \\
(24.6-30.5)\end{array}$ & $\begin{array}{c}28.1 \\
(24.7-31.0)\end{array}$ & $\begin{array}{c}26.3 \\
(22.5-30.0)\end{array}$ & $\begin{array}{c}26.1 \\
(24.3-30.8)\end{array}$ & 0.298 & \\
\hline $\mathrm{FEV}_{1}(\mathrm{~L})$ & $\begin{array}{c}2.70 \\
(2.14-3.34)\end{array}$ & $\begin{array}{c}2.89 \\
(2.38-3.66)\end{array}$ & $\begin{array}{c}2.04 \\
(1.48-2.58)\end{array}$ & $\begin{array}{c}2.44 \\
(2.02-3.05)\end{array}$ & 0.000 & $\begin{array}{c}0.015^{\mathrm{a}}, 0.16^{\mathrm{b}} \\
\quad<0.001^{\mathrm{c}}\end{array}$ \\
\hline $\mathrm{FEV}_{1}(\%$ of predicted) & $91.5(76-103.5)$ & $96(85-110)$ & $71(56-79)$ & $82(72-102)$ & 0.000 & $\begin{array}{l}0.01^{\mathrm{a}}, 0.01^{\mathrm{b}} \\
<0.001^{\mathrm{c}}\end{array}$ \\
\hline $\mathrm{FVC}(\mathrm{L})$ & $\begin{array}{c}3.78 \\
(3.16-4.56)\end{array}$ & $\begin{array}{c}3.84 \\
(3.16-4.80)\end{array}$ & $\begin{array}{c}3.73 \\
(2.50-4.26)\end{array}$ & $\begin{array}{c}3.65 \\
(3.25-4.41)\end{array}$ & 0.406 & \\
\hline FVC ( $\%$ of predicted) & $102(91-115.5)$ & $104(92-116)$ & $99(90-102)$ & $103(87-120)$ & 0.106 & \\
\hline $\mathrm{FEV}_{1} \% \mathrm{FVC}$ & 73 (67-78) & $76(72-80)$ & $56(51-65)$ & $69(66-70)$ & 0.000 & $\begin{array}{c}<0.001^{\mathrm{a}} \\
0.05^{\mathrm{b}} \\
<0.001^{\mathrm{c}}\end{array}$ \\
\hline $\begin{array}{l}\text { Ex-smokers/ } \\
\text { /current smokers (n) }\end{array}$ & $39 / 139$ & $26 / 93$ & $2 / 20$ & $11 / 26$ & 0.179 & \\
\hline Pack-years & $28(18-38)$ & $22.5(15-36)$ & $33.5(30-40)$ & $30(22-40)$ & 0.003 & $\begin{array}{c}0.01^{\mathrm{a}}, 0.19^{\mathrm{b}} \\
1.0^{\mathrm{c}}\end{array}$ \\
\hline CAT (points) & $8(3-13)$ & $6(3-12)$ & $11(8-17)$ & $9(4-16)$ & 0.013 & $\begin{array}{c}0.43^{\mathrm{a}}, 0.52^{\mathrm{b}} \\
0.02^{\mathrm{c}}\end{array}$ \\
\hline mMRC & $0(0-1)$ & $0(0-1)$ & $0.5(0-1)$ & $0(0-1)$ & 0.580 & \\
\hline COPD n (\%) & $5(3)$ & 0 & $5(23)$ & $0(0)$ & 0.000 & \\
\hline Asthma $\mathrm{n}(\%)$ & $5(3)$ & $3(2.5)$ & $2(9)$ & 0 & 0.174 & \\
\hline Hypertension n (\%) & $67(39)$ & $45(38)$ & $7(32)$ & $15(40.5)$ & 0.798 & \\
\hline Ischemic heart disease $\mathrm{n}(\%)$ & $20(12)$ & $12(10)$ & $1(4.5)$ & $7(19)$ & 0.170 & \\
\hline
\end{tabular}

The results are presented as median (IQR) or numbers. For comparisons with no significance in the Kruskal-Wallis test, only one $\mathrm{p}$-value is shown, the left $\mathrm{p}$ column; for comparisons with significance, $p$-values are shown for each compared pair, the right p column: a (N vs $A 0)$; b (N vs PAO); c (AO vs PAO).

AO - airway obstruction; BMI — body mass index; CAT — COPD Assessment Test; FEV $_{1}$ - forced expiratory volume at 1 second; FVC — forced vital capacity; mMRC — Medical Research Council scale of dyspnea; N — normal; PAO — possible airway obstruction

patients evaluated according to the mMRC dyspnea scale $(\mathrm{p}<0.001)$.

\section{Discussion}

Our study is one of the few reports, which show the results of public spirometry carried out outside a health care setting. We demonstrated that despite an active search for individuals at risk, the readiness to take part in a simple screening program that involved a questionnaire and public spirometry reached only $20 \%$. In 178 subjects who entered the screening program realized by medical students trained to perform and interpret spirometry, airway obstruction and possible airway obstruction were found in $33 \%$ of the respondents. Importantly, only $25 \%$ of those who were informed about an abnormal spirometry result, and were invited to a reference pulmonary center to undergo stationary spirometry and to be consulted by pulmonary specialist, attended the visit. Those patients, who followed the students' advice and came for a second assessment were older and were ex-smokers rather than active smokers. We did not demonstrate that the severity of symptoms was associated with the attendance at the follow-up visit in the reference health care pulmonary center.

It seems that active campaigns including spirometry screening in high risk populations might help to manage the important problem of COPD underdiagnosis and, in consequence, to provide a more efficient health care for COPD patients. We found that our program not only allowed to assess 
Table 2. Comparison of the selected clinical data of patients with $A O$ and PAO found in public spirometry who underwent and did not undergo follow up visit

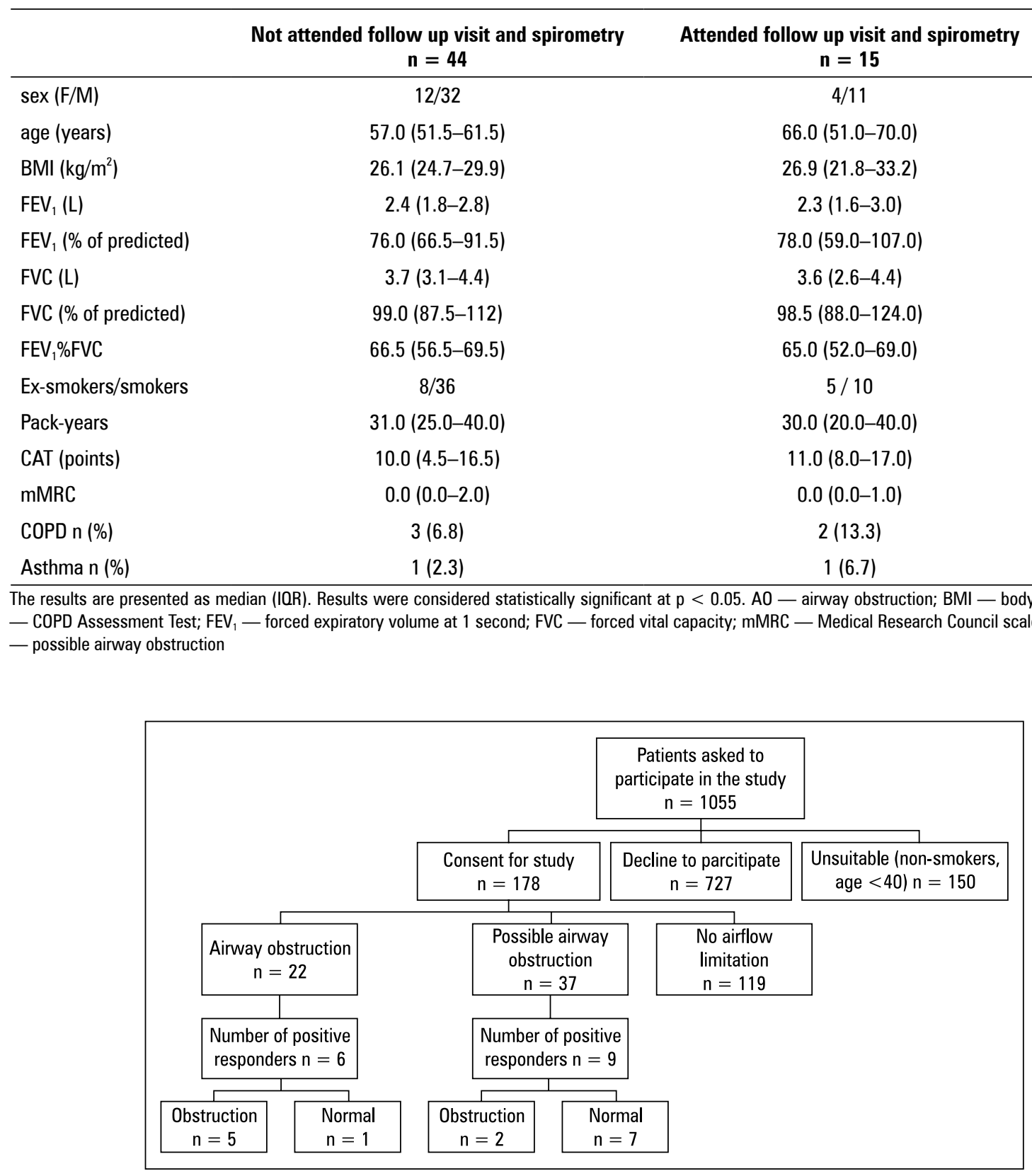

Figure 1. Flow chart presenting the number of patients and the results of spirometry in the subsequent phases of the study

symptoms and perform a screening spirometry, but also to carry out an anti-tobacco educational campaign and to discuss threats related to smoking. To our knowledge, most of the previous studies were performed in primary care setting with active patient recruitment through invitation letters sent by post, telephone calls, advertisements or encouragements during primary care visits [13]. Different patient characteristics and different model of screening can be responsible for significant variability in the response rate found in public campaigns and in screening programs conducted in health care centers. For example, approximately $70 \%$ of potentially eligible participants were recruited by general practitioners in one recent Croatian study aimed at the evaluation of the diagnostic accuracy of active screening for COPD [14], while the respective percentage in our public project conducted by medical students was much lower and did not exceed $20 \%$. Acceptable response rates vary depending on the method of recruitment applied. 


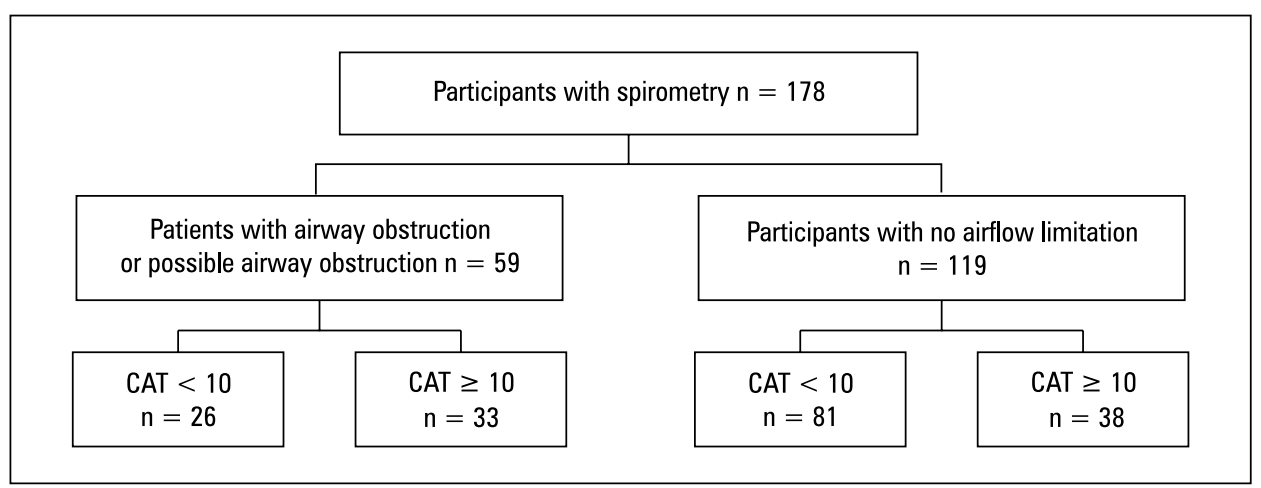

Figure 2. Distribution of the analyzed group depending on the grade of the intensity of the symptoms evaluated in COPD Assessment Test

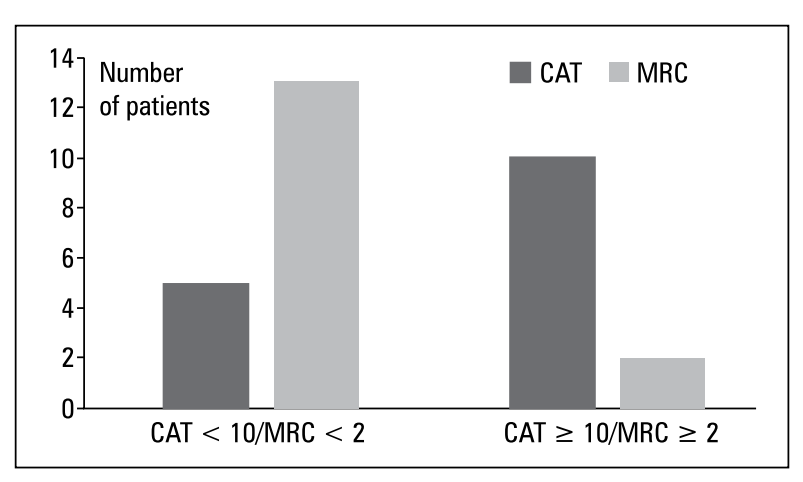

Figure 3. The differences between the results of symptoms scoring with $\mathrm{mMRC}$ and CAT in 15 patients who attended follow-up visit

It is thought that $50 \%$ is an adequate response rate in patients invited to participate by mail and $80 \%$ is considered satisfactory when the recruitment is conducted on a phone call basis. When face-to-face contact is applied in the recruitment phase, the expected response rate can be as high as $80-85 \%$ [15]. Thus, it must be admitted that our response rate of $20 \%$ was unexpectedly low. This can be explained by several factors. First, the passers-by recruited at the railway station represent a fairly specific study group, not necessarily caring for their health. Second, the railway station is a busy place, where the majority of people are in hurry to catch their trains, trams and buses and, therefore, they were reluctant to stop by in spirometry stand. Third, young medical students might have been considered not competent enough to perform spirometry screening. This might have resulted in lower credibility of the campaign, at least for some people who declined to join the study. Finally, winter and spring months with relatively low external temperature were probably an unfavorable time to convince the passers-by to participate in the project.

Low willingness to participate in screening programs is not a specific feature of patients with high risk of pulmonary diseases. In one Polish study, only 169 of 850 (20\%) patients with various gastrointestinal symptoms agreed to undergo gastroscopy. The respective percentage was higher, but still relatively low (62\%), in patients with alarming symptoms [16]. As even the risk of malignancy does not prompt patients to accept screening tests, the response rate of $20 \%$ found in our study performed in busy area might not be as low as it seems at the first glance.

Numerous previous studies demonstrated a high burden of COPD and emphasized the proportion of undiagnosed patients. In a German cohort, the prevalence of COPD classified as GOLD stage I was estimated at $9 \%$, but in the Hokkaido cohort, this value reached even $26 \%$ [17, 18]. In one recent study by Fu et al. [10] undiagnosed airway obstruction was demonstrated in $14.6 \%$ of patients attending primary care, who had a positive smoking history and were older than 30 years. Lokke et al. [20] showed that $21.7 \%$ of 4049 subjects at-risk had been newly diagnosed with COPD in a primary care-setting and the majority of these patients had mild to moderate disease. In one earlier Polish study that applied spirometry screening to detect early stages of COPD in high-risk populations ( $\mathrm{n}=11027$ ), airway obstruction was found in $30.6 \%$ of subjects aged $>40$ years with a smoking history of 10 pack-years or longer [21]. In our study, the sample size was significantly smaller, but the same inclusion criteria identifying high risk population were applied. Excluding 5 patients with known COPD and 5 patients with asthma and assuming $83 \%$ of correct diagnoses of airflow limitation in AO group and $22 \%$ of correct diagnoses in PAO group, it may be speculated that simple public spirometry performed by medical students can correctly identify $11-12 \%$ of subjects in high risk population who had undiagnosed persistent airway obstruction consistent with COPD.

Spirometry continues to be an underutilized tool, despite its ease of use and increased ava- 
ilability in primary care. Portable spirometers can be conveniently used during screening programs and spirometry testing do not necessarily need to be performed indoors [22]. The results of previous studies pointed out that active case finding in a population at risk for COPD should be instituted, even using a pocket screening spirometer/peak flowmeter [14, 23]. High correlations between the results of pulmonary function measured with Spirobank hand-held spirometer and Jaeger MasterScope in a laboratory environment were demonstrated [24]. Although the number of patients who had undergone both screening and stationary spirometry in our study was relatively low, the differences between $\mathrm{FEV}_{1}$ and FVC measured in these two different settings were irrelevant, $p=0.30$ and $p=0.79$ respectively. It is believed that spirometry used for screening purposes requires a verification in a specialized health center. In our study, such approach was particularly important in patients with public spirometry classified as possible airway obstruction. Airway obstruction was confirmed in only $22 \%$ of these patients. On the other hand, airflow limitation was confirmed by stationary spirometry in as many as 5/6 (83\%) of patients whose earlier public spirometry was classified as airway obstruction. These data show that public spirometry performed with a portable spirometer might be a reliable screening tool for patients with COPD.

Our results indicate that in the population older than 40 years with a smoking history of $>10$ pack-years, extrapolated prevalence of airway obstruction reaches $14.6 \%$, whereas the percentage of subjects with a new diagnosis of airway obstruction is approximately $10.7 \%$. Dąbrowiecki et al. [25] found that airway obstruction is present in $34 \%$ of the subjects participating in the Polish Spirometry Day, a national multicenter campaign. Such results point out a significant underestimation of the number of patients with obstructive lung diseases in clinical practice. Knowing how low percentage of people are willing to perform spirometry during a public campaign, it would be advisable to search for more effective methods to recruit high risk patients into spirometry screening programs.

In our study, subjects with airway obstruction or possible airway obstruction had a significantly higher CAT score than those with normal spirometry results. We have also shown that a significantly higher percentage of symptomatic patients were identified with the use of the CAT compared to the use of the mMRC scale. This might be easily explained in the light of the results of earlier studies that found a relatively weak correlation between mMRC and CAT [26, 27] and demonstrated that the CAT score correlates much better with St. George's Respiratory Questionnaire (SGRQ) [26]. Disagreement between CAT and mMRC results is not surprising because these two instruments differ in their purpose and symptom areas that are covered. CAT score and its items "breathlessness" and "phlegm" were significantly related to spirometric diagnosis of COPD in a population-based sample of 532 participants [28].

We are aware about some limitations of the study that should be mentioned. The major limitation is probably one of the study results, i.e. the low percentage of passers-by who agreed to participate in the study. A similar statement refers to the low percentage of patients who attended follow-up visit and underwent stationary spirometry verifying the results of public spirometry. The low number of patients in whom reliable conclusion from pulmonary function testing could have been established (certain airflow limitation or normal spirometry) did not allow to draw any reliable epidemiological conclusions. Possible causes of this situation have already been presented when discussing the low response rate in our study. Complex diagnostic criteria for airway obstruction, with patients classification as having airway obstruction or possible airway obstruction, may be considered as one of the study limitations. We realize that the quality of public spirometry may be suboptimal and the results of $\mathrm{FEV}_{1} / \mathrm{FVC}<0.7$ in symptomatic patients unable to perform spirometry of good quality should be a subject of particular concern. Hence, these cases were classified as possible airway obstruction and were to be verified during the second phase of the study. Unfortunately, the percentage of patients who responded to our invitation to perform high quality stationary spirometry was surprisingly low.

\section{Conclusions}

The limited willingness of subjects at risk for COPD development to participate in public spirometry campaign may indicate that this is not an effective form of COPD screening. Smokers are rather reluctant to undergo complimentary spirometry and pulmonary consultation, even in the presence of pronounced respiratory symptoms. Nevertheless, the study showed the incidence of non-diagnosed airway obstruction in smokers aged $>40$ years $10.7 \%$. We also demonstrated 
that a short training performed by experienced technicians seems sufficient for persons who are not healthcare providers to perform quality spirometry and to obtain reliable results. Our observations may be helpful in elaborating screening programs for COPD.

\section{Conflict of interest}

The authors declare no conflict of interest.

\section{References:}

1. Rabe KF, Hurd S, Anzueto A, et al. Global Initiative for Chronic Obstructive Lung Disease. Global strategy for the diagnosis, management, and prevention of chronic obstructive pulmonary disease: GOLD executive summary. Am J Respir Crit Care Med. 2007; 176(6): 532-555, doi: 10.1164/rccm.200703-456SO, indexed in Pubmed: 17507545.

2. Adeloye D, Chua S, Lee C, et al. Global Health Epidemiology Reference Group (GHERG). Global and regional estimates of COPD prevalence: Systematic review and meta-analysis. J Glob Health. 2015; 5(2): 020415, doi: 10.7189/jogh.05-020415, indexed in Pubmed: 26755942.

3. Diaz-Guzman E, Mannino DM. Epidemiology and prevalence of chronic obstructive pulmonary disease. Clin Chest Med. 2014; 35: 7-16.

4. Nizankowska-Mogilnicka E, Mejza F, Buist AS, et al. Prevalence of COPD and tobacco smoking in Malopolska region results from the BOLD study in Poland. Pol Arch Med Wewn. 2007; 117(9): 402-410, indexed in Pubmed: 18062562.

5. Pływaczewski R, Maciejewski J, Bednarek M, et al. Prevalence, severity and underdiagnosis of COPD in the primary care setting. Thorax. 2008; 63(5): 402-407, doi: $10.1136 /$ thx.2007.085456, indexed in Pubmed: 18234906.

6. Pływaczewski R, Bednarek M, Jonczak L, et al. Prevalence of COPD in Warsaw population. Pneumonol Alergol Pol. 2003; 71(7-8): 329-335, indexed in Pubmed: 15052966.

7. Sliwiński P, Górecka D, Jassem E, et al. Polish respiratory society guidelines for chronic obstructive pulmonary disease. Pneumonol Alergol Pol. 2014; 82(3): 227-263, doi: 10.5603/ PiAP.2014.0030, indexed in Pubmed: 24793150.

8. Polakowska M, Kaleta D, Piotrowski W, et al. Tobacco smoking in Poland in the years from 2003 to 2014. Multicentre National Population Health Examination Survey (WOBASZ). Pol Arch Intern Med. 2017; 127(2): 91-99, doi: 10.20452/pamw.3896, indexed in Pubmed: 28224973.

9. Price D, Crockett A, Arne M, et al. Spirometry in primary care case-identification, diagnosis and management of COPD. Prim Care Respir J. 2009; 18(3): 216-223, doi: 10.4104/ pcri.2009.00055, indexed in Pubmed: 19688142.

10. Miller MR, Hankinson J, Brusasco V, et al. ATS/ERS Task Force. Standardisation of spirometry. Eur Respir J. 2005; 26(2): 319-338, doi: 10.1183/09031936.05.00034805, indexed in Pubmed: 16055882 .

11. Pellegrino R, Viegi G, Brusasco V, et al. Interpretative strategies for lung function tests. Eur Respir J. 2005; 26(5): 948-968, doi: 10.1183/09031936.05.00035205, indexed in Pubmed: 16264058.

12. Sterk PJ, Fabbri LM, Quanjer PH, et al. Standardized lung function testing. Report working party. Bull Eur Physiopathol Respir. 1983; 19 Suppl 5: 1-95, indexed in Pubmed: 6616097.

13. Haroon SMm, Jordan RE, O'Beirne-Elliman J, et al. Effectiveness of case finding strategies for COPD in primary care: a systematic review and meta-analysis. NPJ Prim Care Respir Med. 2015; 25: 15056, doi: 10.1038/npipcrm.2015.56, indexed in Pubmed: 26313400.
14. Labor M, Vrbica Ž, Gudelj I, et al. Diagnostic accuracy of a pocket screening spirometer in diagnosing chronic obstructive pulmonary disease in general practice: a cross sectional validation study using tertiary care as a reference. BMC Fam Pract. 2016; 17(1): 112, doi: 10.1186/s12875-016-0518-8, indexed in Pubmed: 27542843 .

15. Shaughnessy JJ, Zechmeister EB, Zechmeister JS. Survy Research. In Research Methods in Psychology. New York 2012: 137-182.

16. Ziółkowski B, Pacholec A, Muszyński J. Alarm symptoms, risk factors for digestive tract cancer and readiness to participate in an endoscopic screening program. Gastroenterology Review. 2013; 2: 108-114, doi: 10.5114/pg.2013.34836.

17. Karch A, Vogelmeier C, Welte T, et al. COSYCONET Study Group. The German COPD cohort COSYCONET: Aims, methods and descriptive analysis of the study population at baseline. Respir Med. 2016; 114: 27-37, doi: 10.1016/j. rmed.2016.03.008, indexed in Pubmed: 27109808.

18. Nishimura M, Makita H, Nagai K, et al. Hokkaido COPD Cohort Study Investigators. Annual change in pulmonary function and clinical phenotype in chronic obstructive pulmonary disease. Am J Respir Crit Care Med. 2012; 185(1): 44-52, doi: 10.1164/rccm.201106-0992OC, indexed in Pubmed: 22016444.

19. Fu SN, Yu WC, Wong CKH, et al. Prevalence of undiagnosed airflow obstruction among people with a history of smoking in a primary care setting. Int J Chron Obstruct Pulmon Dis. 2016; 11: 2391-2399, doi: 10.2147/COPD.S106306, indexed in Pubmed: 27729780.

20. Løkke A, Ulrik CS, Dahl R, et al. TOP GOLD study-group. Detection of previously undiagnosed cases of COPD in a high-risk population identified in general practice. COPD. 2012; 9(5): 458-465, doi: 10.3109/15412555.2012.685118, indexed in Pubmed: 22643016.

21. Zielinnski J, Bednarek M. Know the Age of Your Lung Study Group. Early detection of COPD in a high-risk population using spirometric screening. Chest. 2001; 119(3): 731-736, indexed in Pubmed: 11243950.

22. Maio S, Sherrill DL, MacNee W, et al. European Respiratory Society/European Lung Foundation Spirometry Tent Working Group. The European Respiratory Society spirometry tent: a unique form of screening for airway obstruction. Eur Respir J. 2012; 39(6): 1458-1467, doi: 10.1183/09031936.00111910, indexed in Pubmed: 22267757.

23. Nelson SB, LaVange LM, Nie Y, et al. Questionnaires and pocket spirometers provide an alternative approach for COPD screening in the general population. Chest. 2012; 142(2): 358366, doi: 10.1378/chest.11-1474, indexed in Pubmed: 22194590.

24. Degryse J, Buffels J, Van Dijck Y, et al. Accuracy of office spirometry performed by trained primary-care physicians using the MIR Spirobank hand-held spirometer. Respiration. 2012; 83(6): 543552, doi: 10.1159/000334907, indexed in Pubmed: 22269344.

25. Dabrowiecki P, Badyda AJ, Chcialowski A, et al. Spirometry day: a means to enhance social knowledge on respiratory diseases. Adv Exp Med Biol. 2013; 788: 213-219, doi: 10.1007/97894-007-6627-3 31, indexed in Pubmed: 23835981.

26. Rhee CK, Kim JW, Hwang YIl, et al. Discrepancies between modified Medical Research Council dyspnea score and COPD assessment test score in patients with COPD. Int J Chron Obstruct Pulmon Dis. 2015; 10: 1623-1631, doi: 10.2147/COPD. S87147, indexed in Pubmed: 26316736.

27. Casanova C, Marin JM, Martinez-Gonzalez C, et al. COPD History Assessment in Spain (CHAIN) Cohort. Differential Effect of Modified Medical Research Council Dyspnea, COPD Assessment Test, and Clinical COPD Questionnaire for Symptoms Evaluation Within the New GOLD Staging and Mortality in COPD. Chest. 2015; 148(1): 159-168, doi: 10.1378/ chest.14-2449, indexed in Pubmed: 25612228.

28. Raghavan N, Lam YM, Webb KA, et al. Components of the COPD Assessment Test (CAT) associated with a diagnosis of COPD in a random population sample. COPD. 2012; 9(2): 175-183, doi 10.3109/15412555.2011.650802, indexed in Pubmed: 22409441. 